6. Utriainen T, Makimattila S, Virkamaki A, Bergholm R, Yki-Jarvinen H (1996) Dissociation between insulin sensitivity of glucose uptake and endothelial function in normal subjects. Diabetologia 39 (12): 1477-1482

7. Vicini P, Bonadonna RC, Utriainen T, Nuutila P, Raitakari M, Yki-Jarvinen H, Cobelli C (1997) Estimation of blood flow heterogeneity distribution in human skeletal muscle from positron emission tomography data. Ann Biomed Eng 25 (5): 906-910

8. Kelley D, Price J, Beattie J, Goodpaster S, Andreko SJ, Jedali F (1997) Analog effects of FDG in human skeletal muscle: physiologic implications of insulin induced reductions of "LC". Diabetologia 40 [Suppl 1]: A4
9. Doenst T, Taegtmeyer H (1998) Profound underestimation of glucose uptake by [18F]2-deoxy-2-fluoroglucose in reperfused rat heart muscle. Circulation 97: 2454-2462

10. Baron AD, Brechtel-Hook G, Johnson A, Cronin J, Leaming R, Steinberg HO (1996) Effect of perfusion rate on the time course of insulin mediated skeletal muscle glucose uptake. Am J Physiol 271: E1067-E1072

11. Utriainen T, Nuutila P, Takala T et al. (1997) Intact insulin stimulation of skeletal muscle blood flow, its heterogeneity and redistribution, but not of glucose uptake in non-insulin-dependent diabetes mellitus. J Clin Invest 100: 777-785

\section{Insulin-mediated vasodilatation: the authors' reply}

\section{Dear Sir,}

We thank Steinberg and Baron for their comments on our review [1]. It is disappointing that the most important message of the review has been missed.

The major difference between the studies by Steinberg and Baron, and those by other investigators is in the design used to study insulin's effect on limb blood flow. In the first study describing a 'physiologic' dose-dependent effect of insulin on limb blood flow in 1990, insulin was infused sequentially in increasing doses for $9 \mathrm{~h}$ (ref. 8 in [1]). Between 5 and $7 \mathrm{~h}$ of insulin infusion, a $40 \%$ increase in blood flow was observed. At $9 \mathrm{~h}$ at an insulin concentration of $17520 \mathrm{pmol} / \mathrm{l}$, flow had increased by $65 \%$ ( $4.3 \mathrm{vs} 2.6 \mathrm{dl} / \mathrm{min})$. These data do not differ from those reported by ourselves using sequential insulin infusions and measurement of forearm blood flow using plethysmography (reproducibility appears to be laboratory-dependent, in our laboratory it is $13 \%$, ref. 19 in [1]): an increase in flow of $50 \%$ at $4 \mathrm{~h}$ (insulin $834 \mathrm{pmol} / \mathrm{l}$ ) and $113 \%$ at $6 \mathrm{~h}$ (insulin $2907 \mathrm{pmol} / \mathrm{l}$ ). The difference between this study and our earlier study cited by Steinberg and Baron [2] is that in the latter study various doses of insulin were infused on separate days rather than sequentially and that basal and insulin stimulated flows were determined in different groups of subjects. After an oral glucose tolerance test in normal middle-aged subjects, insulin concentrations increase to a mean peak concentration of $360 \mathrm{pmol} / \mathrm{l}$ after $1 \mathrm{~h}$ and return to baseline by $3 \mathrm{~h}$ [3]. In our view, the latter conditions represent physiology. In the review, we analysed data from 75 studies just in normal subjects and showed that under conditions we consider physiological (dose * duration of insulin infusion $<1$, Fig. 2 in [1]), blood flow was unchanged. Taken together these data indicate that the duration of the insulin infusion rather than the method is the most important determinant of the blood flow response to insulin. Along the same lines, even investigators using the same technique as Steinberg and Baron (ref.11 in [1]) or different techniques (refs.12, 71-74 in [1]), have failed to find a defect in insulin stimulated blood flow in patients with Type II (non-insulin-dependent) diabetes mellitus. This again shows that results regarding flow are not technique-dependent. The discrepant data might be explained by factors such as limb muscularity and muscle capillary density (refs. 19 and 26 in [1]), which explain more than $70 \%$ of interin-

Corresponding author: Dr. H. Yki-Järvinen, Department of Medicine, Division of Endocrinology and Diabetes, University of Helsinki, Haartmaninkatu 4, FN-00029 Huch, Finland dividual variation in basal flow and of flow responses to insulin measured with plethysmography. The latter data further support the validity of the technique.

Regarding the question of whether insulin-mediated vasodilatation contributes to glucose uptake, we would agree that resolution of controversy occurs through independent confirmation and new methodologies. In this respect, the authors correctly observe that their finding of a change in glucose uptake in response to a change in flow has not been reproduced in 3 studies cited in the review (refs. 80, 82, 83 in [1]) or in 3 subsequent studies [4-6]. How many repeated attempts do we need? The flow intervention studies include our studies where positron emission tomography (PET), $\left[{ }^{15} \mathrm{O}\right]-\mathrm{H}_{2} \mathrm{O}$ and the autoradiographic method has been used to measure blood flow directly in skeletal muscle. Steinberg and Baron appear to have missed validation of this method [7]. Regarding the ability of $\left.{ }^{[18} \mathrm{F}\right]-$ FDG and PET to accurately trace glucose uptake in skeletal muscle, again the statement of lack of validation is simply scientifically unfounded. The validation includes comparison of PET measurements with traditional measurements using the Fick principle [8] and direct determination of the lumped constant in the presence and absence of insulin in human skeletal muscle (ref. [9]). In our experience, the regression equation relating muscle glucose uptake measured with PET in any group of subjects [normal men and women, obese, hypertensive and Type I (insulin-dependent) and II diabetic patients] is close to that measured independently with the euglycaemic clamp technique and reproducible. This technique also offers the unique possibility to measure glucose uptake without invasive femoral artery and vein catheterizations anywhere in skeletal muscle. We do not understand why Steinberg and Baron consider these human data in skeletal muscle invalid because of strange results obtained in the isolated perfused rat heart preparation. In support of the peculiarities of the former preparation, $\left[{ }^{18} \mathrm{~F}\right]-\mathrm{FDG}$ has recently been shown to accurately trace glucose metabolism even in the human heart in vivo both under fasting and various insulin stimulated conditions [10].

In conclusion, we do not regard the data of Steinberg and Baron to be inconsistent with data generated by other investigators, when the multiple aspects listed in the review, especially the time-dependency of the phenomenon, are carefully considered. The only discrepancy seems to be confined to studies examining whether glucose uptake can be altered by changing blood flow. In any event, we believe the time has come to proceed from trying to explain muscle glucose uptake with blood flow changes induced by insulin to clinically more relevant questions such as why blood vessels stiffen and develop atherosclerosis in insulin resistant people.

Yours sincerely,

H. Yki-Järvinen, T. Utriainen 


\section{References}

1. Yki-Järvinen H, Utriainen T (1998) Insulin-induced vasodilatation: physiology or pharmacology? Diabetologia 41: 369-379

2. Yki-Järvinen H, Young AA, Lamkin C, Foley JE (1987) Kinetics of glucose disposal in whole body and across the forearm in man. J Clin Invest 79: 1713-1719

3. Mitrakou A, Kelley D, Veneman T et al. (1990) Contribution of abnormal muscle and liver metabolism to postprandial hyperglycemia in NIDDM. Diabetes 39: 1381-1390

4. Tack CJ, Lutterman JA, Vervoot G, Thien T, Smits P (1996) Activation of the sodium-potassium pump contributes to insulin-induced vasodilatation in humans. Hypertension 28: 426-432

5. Natali A, Quinones Galvan A, Pecori G, Sanna G, Toschi E, Ferrannini E (1998) Vasodilatation with sodium nitroprusside does not improve insulin action in essential hypertension. Hypertension 31: 632-636
6. Laine H, Yki-Järvinen H, Kirvelä O et al. (1998) Insulin resistance of glucose uptake in skeletal muscle cannot be ameliorated by enhancing endothelium-dependent blood flow in obesity. J Clin Invest 101: 1156-1162

7. Ruotsalainen U, Raitakari M, Nuutila P, Olkonen V, Teräs M, Iida H (1997) Quantitative blood flow measurement of skeletal muscle using ${ }^{15}$-oxygen-water and PET. J Nucl Med 38: 314-319

8. Nuutila P, Koivisto VA, Knuuti J et al. (1992) Glucose-free fatty acid cycle operates in human heart and skeletal muscle in vivo. J Clin Invest 89: 1767-1774

9. Utriainen T, Lovisatti S, Mäkimattila S et al. (1998) Direct measurement of the lumped constant for $1-\left[{ }^{14} \mathrm{C}\right]-2$-deoxyglucose in vivo in human skeletal muscle. Diabetologia 41: A187

10. Ng CK, Soufer R, McNulty PH (1998) Effect of hyperinsulinemia on myocardial fluorine-18-FDG uptake. J Nucl Med 39: 379-383

\section{Nutrient channelling-regulated peroxisome proliferator-activated receptor- $\gamma-2$ (PPAR $\gamma$-2) and leptin gene expression in human subcutaneous fat}

\section{Dear Sir,}

It is widely accepted that obesity, defined as a state of pathologically excessive adipose tissue mass, has major adverse medical consequences, largely due to its association with noninsulin-dependent diabetes, hypertension, hyperlipidaemia, and cardiovascular diseases. The development of obesity requires the continuous differentiation of new adipocytes or their growth or both to store energy as triglycerides [1]. Together with food intake and energy expenditure, partitioning to fat (i.e. the metabolic tendency to deposit excess calories as fat rather than as protein or glycogen) is a third factor regulating body energy homeostasis. This process can be changed in obesity. Little is known about the mechanisms involved in the preferential channelling of different fuels to fat and whether or how the target tissue participates in this process. Increasing evidence indicates that adipocyte may function as a finely regulated endocrine cell containing several factors that play an active part in the regulation of energy homeostasis. One such factor is leptin which is encoded by the $o b$ gene and induces satiety together with an increase in energy expenditure, thereby regulating the size of body fat according to the lipostatic model [2]. The target tissue for these leptin actions is the hypothalamus, in which specific receptors have been identified. Moreover leptin has a dose-dependent lipolytic activity suggesting an autocrine/paracrine action of leptin on white fat cells and the involvement of the $o b$ protein not only in centrally mediated pathways but also in physiological functions which take place peripherally [3].

Adipocyte differentiation from preadipocytes has been shown to be triggered by members of the peroxisome proliferator-activated receptor (PPAR $\gamma)$ [4],which acts through transactivation of adipose specific genes, including those that en-

Corresponding author: Dr. R. Vettor, Department of Medical and Surgical Sciences, University of Padua, Via Ospedale, 105, I-35128 Padua, Italy code for proteins involved in lipid storage and metabolism [5]. In particular, PPAR $\gamma$ - 2 has been shown to have the highest adipogenic activity [6].

PPAR $\gamma-2$ gene expression in adipose tissue is increased as a function of body mass index (BMI) in obese humans and down-regulated in obese patients loosing weight under low calorie diet suggesting a possible role for PPAR $\gamma-2$ expression in the pathogenesis of changed adipocyte numbers and functions in obesity [7].

It has recently been reported in rats that muscle and fat cells have a nutrient-sensing pathway that involves UDP-Nacetylglucosamine and is activated by non-esterified fatty acids (NEFA) [1] and which stimulates the gene expression of leptin [2].

To investigate in humans whether others nutrient-sensing pathways may be activated by NEFA [8], we examined the expression of genes coding for the adipose satiety hormone leptin and the adipogenesis stimulant PPAR $\gamma-2$ [9] in the gluteal subcutaneous fat of eight male volunteers of normal-weight (age 28-43; mean BMI $22.6 \pm 0.9 \mathrm{~kg} \times \mathrm{m}^{-2}$ ) before and after Intralipid plus heparin infusion.

Protocols involving adipose biopsies have been approved by an internal ethics committee of the University of Padua and all subjects gave their informed consent.

Intralipid $20 \%$, a commercial emulsion of soybean oil, was infused at $1.5 \mathrm{ml} \times \mathrm{min}^{-1}\left(0.3 \mathrm{~g} \times \mathrm{min}^{-1}\right)$ with heparin sodium ( $200 \mathrm{U}$ in bolus and $0.4 \mathrm{U} \times \mathrm{min}^{-1} \times \mathrm{kg}^{-1}$ iv) for $5 \mathrm{~h}$. Heparin displaces lipoprotein lipase (LPL) from adipocyte surface proteoglycan binding sites and increases LPL-specific triglyceride hydrolysing activity. Gluteal subcutaneous fat was obtained by needle liposuction after an overnight fast and after Intralipid plus heparin infusion. The tissue was immediately frozen in liquid nitrogen. Total RNA was isolated from adipose tissue biopsies of treated or untreated patients using the RNAzol method (TM Cinna Scientific, Friendswood, Tex., USA). The RNAs were treated for $1 \mathrm{~h}$ at $37^{\circ} \mathrm{C}$ with $6 \mathrm{U}$ RNAse-free DNAse I/ $\mu \mathrm{g}$ RNA in $100 \mathrm{mmol} / \mathrm{l}$ Tris- $\mathrm{HCl}, \mathrm{pH}$ 7.5 , and $50 \mathrm{mmol} / 1 \mathrm{MgCl}_{2}$ in the presence of $2 \mathrm{U} / \mu \mathrm{l}$ placenta RNAse inhibitor. All of RNAs (circa $200 \mathrm{ng}$ from each biopsies) were reverse-transcribed with $200 \mathrm{U}$ of Moloney murine leukemia virus reverse transcriptase (Promega, Madison, Wis., USA) in $20 \mu \mathrm{l}$ of buffer containing $0.4 \mathrm{mmol} / \mathrm{l} \mathrm{dNTPs}, 2$ $\mathrm{U} / \mathrm{ml}$ RNAse inhibitor, $0.8 \mu \mathrm{g}$ oligo $(\mathrm{dT})_{15}$ primer (Promega). Reverse transcription-polymerase chain reaction (RT-PCR) was done using Taq DNA polymerase (Promega) in $25 \mu \mathrm{l}$ of 